\title{
Temporal variation in genetic structure of a colonising species: Aedes albopictus in the United States
}

\author{
Srinivas Kambhampati*† \\ William C. Black IV,*§ \\ Karamjit S. Rai* and \\ Daniel Sprengerł
}

\author{
* Department of Biological Sciences, University of \\ Notre Dame, Notre Dame, Indiana 46556 U.S.A. \\ $\$$ Harris County Mosquito Control District, Houston, \\ Texas 77054 U.S.A.
}

The medically important mosquito, Aedes albopictus, has recently become established in several locations within the United States. A three-year survey of temporal variation in allele frequencies at ten enzymatic loci in 17 populations was undertaken to determine the extent and direction of change since the colonisation event. Significant, but nondirectional, changes were detected in allele frequencies at most of the loci in all populations. Some alleles detected at low frequencies in earlier samples were not found in subsequent samples. Variance of allele frequencies remained unchanged. In at least two locations, there was an increase in mean heterozygosity, perhaps because of gene flow. There was no significant change in the levels of genetic variation within and among populations. The results from this study indicate that the breeding structure of Ae. albopictus in the U.S. did not differ substantially from that in a native habitat, either soon after colonisation or after several generations in the new habitat. We suggest that a large founder population, gene flow and a rapid population expansion could explain the present breeding structure of $A e$. albopictus.

\section{INTRODUCTION}

We have been studying the population genetics of Aedes albopictus (Skuse) (Diptera: Culicidae), a medically important mosquito, since its introduction into the U.S. in the early 1980s (Black et al., 1988a, b, 1989). Ae. albopictus has historically been a successful coloniser (see Hawley 1988). Although there have been a few small introductions into the U.S. in the last few years (Eads, 1972; Reiter and Darsie, 1984), a large breeding population was discovered for the first time in Harris County, Texas, in August 1985 (Sprenger and Wuithiranyagool, 1986). The mosquito was probably introduced as eggs or larvae in used tyres shipped from Asia (Craven et al. 1987); diapause profiles and allozyme analysis suggest northern Japan as their most likely origin (Hawley et al., 1987; Kambhampati et al., in preparation). The present distribution of Ae, albopictus in the U.S. includes some 20 southeastern, north-eastern and midwestern states (Centers for Disease Control, 1987).

† To whom correspondence should be addressed.

$\S$ Present address: Department of Entomology, Kansas State University Manhattan KS 66506 U.S.A.
Previous studies on Ae. albopictus (Black et al. $1988 a, b)$ from the U.S. and southeast Asia revealed that genetic drift at the local level is integral to its natural breeding structure. That is, in both habitats, most of the variation in allele frequencies arises from the within population component and the high variance within populations in the U.S. is not a consequence of the recent colonisation. Mean heterozygosity of U.S. populations was also comparable to that in one native habitat, suggesting the possibility of an unusually large founder population.

Given this information, we wished to determine the extent and the direction of change in allele frequencies of the U.S. populations of Ae. albopictus since the first sampling in 1986. Spatial and temporal variation inallele frequencies of $17 \mathrm{popu}$ lations was studied over three years to determine if there was a change in local breeding structure and/or in the levels of genetic variation since the colonization. If genetic drift at the local level is still continuing, a large proportion of the variance in allele frequncies would be attributable to variation among locations within cities as reported by Black et al. (1988a). If there were "founder effects" (Mayr, 1963) directly associated with the colonisation, there might be a decrease over time in within 
population genetic variation and a concurrent increase in between population genetic variation through a random loss or fixation of alleles.

We undertook a nested spatial sampling of populations (Black et al., 1988a, b, 1989) which involved sampling a number of cities and several locations within some of those cities. This design may enable one to detect drift at the local level by the partitioning of variance in allele frequencies into two components, among locations within cities and among cities. Random loss or fixation of alleles among the U.S. populations as a whole can be detected by estimating measures of within and between population variation, i.e., mean expected heterozygosity and genetic distances, respectively.

Studies of genetic structure of colonising species often suggest a decrease in genetic variation resulting from drift, but only in populations several hundred generations removed from the original founders (e.g., Bryant et al., 1981; Easteal, 1988; Johnson, 1988; Schwaegerle and Schaal, 1979; Taylor and Gorman, 1975). The discovery of $A e$. albopictus soon after its arrival to the U.S. gives an opportunity to study the genetics of this species during the process of colonisation and to obtain a better understanding of the relative importance of the various evolutionary mechanisms in speciation and in the biological control of insect pests, which often involves the deliberate introduction of exotic species.

\section{MATERIALS AND METHODS}

Samples of Ae. albopictus were collected twice a year in and around Harris County, Texas. Ae. albopictus was first reported in large numbers from a location within Harris County (Sprenger and Wuithiranyagool, 1986). Samples were collected once in late June/early July and again in late September/early October of the same year between 1986 and 1988. The number of sites sampled in Texas ranged from eight to 12 . To obtain a measure of change in allele frequencies of US populations outside Texas, samples were collected in five different sites in the southeast, once in the summer of 1986 and again in the summer of 1988. These sites included three locations within the city of New Orleans, Louisiana, and one each in Jacksonville, Florida and Memphis, Tennessee (fig. 1 and table 1).

Eggs were collected in the field and were reared to adulthood (parentals) in an insectary at $27 \pm 1^{\circ} \mathrm{C}$ 80 per cent $\mathrm{RH}$ and $12 \mathrm{~h} \mathrm{~L}: 12 \mathrm{~h} \mathrm{D}$ diel cycle. The number of larvae hatched from each location ranged from about 50 to a few hundred. Individuals assayed in 1986 consisted of the parentals. In subsequent assays, the parentals were allowed to mate and oviposit freely in a large cage and the $F_{1}$ adults were assayed.

Ten polymorphic loci were resolved for each population and sampling date using the Hoeffer SE600 vertical polyacrylamide gel electrophoresis

Table 1 Location and dates at which Aedes albopictus samples were collected in Texas and elsewhere in the United States. + indicates that a sample was obtained and - indicates that a sample could not be obtained

\begin{tabular}{|c|c|c|c|c|c|}
\hline \multirow[b]{2}{*}{ Location } & \multicolumn{5}{|c|}{ Sampling date } \\
\hline & Summer 86 & Summer 87 & Fall 87 & Summer 88 & Fall 88 \\
\hline \multicolumn{6}{|l|}{ Texas } \\
\hline Chambers & + & - & + & + & + \\
\hline Galveston & + & + & + & + & + \\
\hline Liberty & + & + & + & + & + \\
\hline Brazoria & - & + & + & + & + \\
\hline Fort Bend & - & + & + & + & + \\
\hline Montgomery & - & - & + & + & + \\
\hline Area 32 & + & + & - & + & + \\
\hline Area 34 & + & + & - & + & + \\
\hline Area 61 & + & + & + & + & - \\
\hline Area 203 & + & + & + & + & + \\
\hline Area 218 & + & + & + & + & + \\
\hline Area 509 & + & + & + & + & + \\
\hline New Orleans site 1 & + & - & - & + & - \\
\hline New Orleans site 2 & + & - & - & + & - \\
\hline New Orleans site 4 & + & - & - & + & - \\
\hline Memphis & + & - & - & + & - \\
\hline Jacksonville & + & - & - & + & - \\
\hline
\end{tabular}

Summer = late June/early July, Fall = late September/early October. 


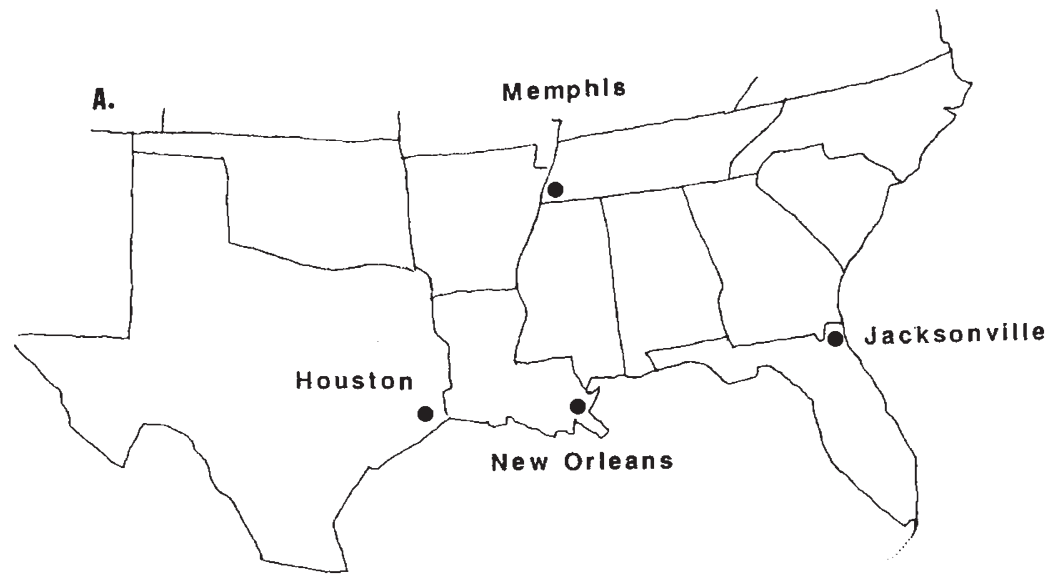

B.

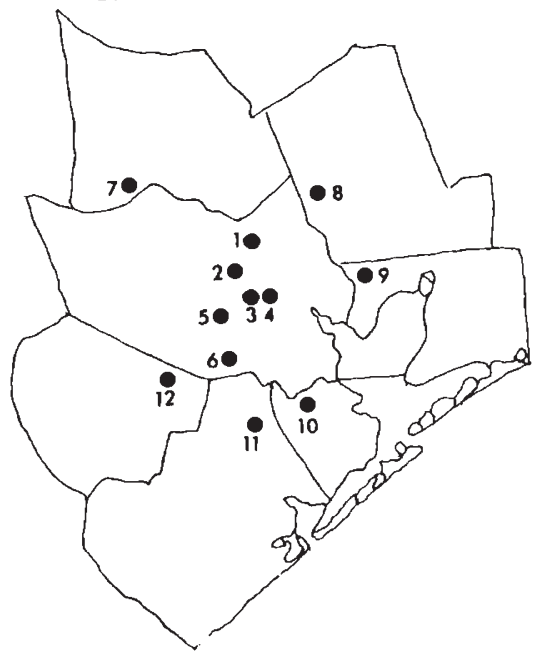

$50 \mathrm{~km}$ c.

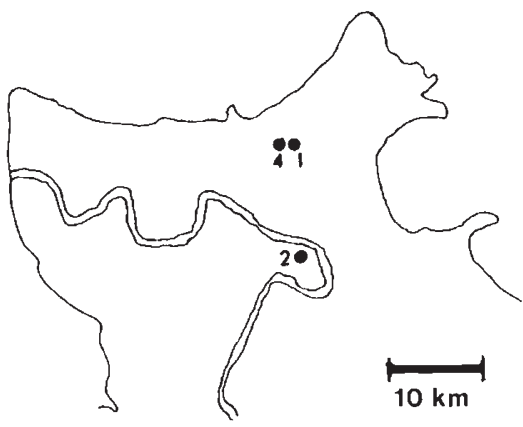

Figure 1 (A) A map of the southern United States showing the four cities in which populations of Aedes albopictus were sampled. (B) Sampling sites in around Harris county, Texas. 1: Area 218, 2: Area 203, 3: Area 32, 4: Area 34, 5: Area 61, 6: Area 509 (all Houston locations), 7: Montgomery county, 8: Liberty county, 9: Chambers county, 10: Galveston county, 11: Brazoria county, 12: Fort Bend county. (C) Sampling sites in the city of New Orleans. 1: New Orleans site 1 (North site), 2: New Orleans site 2 (Algiers) 4: New Orleans site 4 (Northwest site).

system. The Tris-citrate (TC) buffer system $(0.78 \mathrm{M}$ Tris, $0 \cdot 24 \mathrm{M}$ monohydrate citric acid, $p \mathrm{H} \mathrm{7 \cdot 2)}$ was used to resolve aconitase (ACON), $\alpha$-glycerophosphate dehydrogenase ( $\alpha$-GPDH), hydroxyl acid dehydrogenase (HAD), Isocitrate dehydrogenase (IDH) and malic acid dehydrogenase (MDH) and the Tris-boric acid-EDTA (TBE) buffer system $(0 \cdot 81 \mathrm{M}$ Tris, $0 \cdot 20 \mathrm{M}$ boric acid, $15 \mathrm{mM}$ EDTA disodium salt, $p \mathrm{H} \mathrm{8.9)}$ was used for esterase (EST), Glutamate-oxaloacetate transaminase (GOT), 6phosphogluconic acid dehydrogenase (6-PGDH), phosphoglucoisomerase (PGI) and phosphoglucomutase (PGM). The alleles were scored with reference to the most common allele $\left(r_{\mathrm{f}}=1 \cdot 0\right)$ from the Memphis, Tennessee population. Mosquitoes were ground in $40 \mu \mathrm{l}$ of grinding buffer (10 per cent sucrose, $0 \cdot 01$ per cent bromophenol blue, 1 per cent triton X-100 dissolved in TC electrode buffer diluted $1: 5$ ).

Allele frequencies and their spatial and temporal heterogeneity were analyzed using BIOSYS1 (Swofford and Selander, 1981). Genetic variation 
was compared within and among populations and over time using bivariate correlation analysis and one-way analysis of variance (ANOVA). Wright's (1978) $F$-statistics were used to partition the variance in allele frequencies into variance among cities and among locations within cities. The data for the 1986 samples have been published by Black et al. $(1988 a)$.

\section{RESULTS}

Allele frequencies are available from the authors upon request. Two loci, Got and $\alpha-G p d h$, were monomorphic in all the populations and were therefore not considered in the analysis.

A contingency $\chi$-square analysis of variation in allele frequencies of each population over time indicated a significant difference $(P<0.05)$ for most of the loci. The allele frequencies at $P g m$, $H a d$ and Est varied significantly over time in $11 / 12$ Texas populations, Acon and Idh in 9/12 populations and $P g d$ and $P g i$ in $6 / 12$ populations. The least variable locus in Texas populations was $M d h$, which varied only in $4 / 12$ populations. The frequencies of the comon alleles remained fairly stable over time in virtually all the populations and the significant differences were due primarily to the presence or absence of rare alleles. Some alleles that were observed at very low frequencies in earlier samples were not detected in subsequent samples. These alleles included the $F$ allele at $P g m$ locus and the $E$ allele at $M d h$ locus in Chambers county, and the $G$ allele at Had locus in Areas 32 and 34 in Houston.

The pattern of allele frequency variation in the five populations outside Texas was similar to that observed within Texas. Allele frequency at the MDH locus did not vary with time in any of the populations. Allele frequencies at the $I d h$ and the $P g i$ loci did not vary significantly in $4 / 5$ populations; those at Acon varied in $2 / 5$ populations and at Est and $\mathrm{Had}$ in $4 / 5$ populations. The sample from New Orleans site 1, which was polymorphic for Idh in 1986, was found to be monomorphic in 1988. As in the Texas populations, there was no observable systematic change in the frequency of alleles at any of the loci studied. Alleles possibly lost include the $F$ allele at $\mathrm{Had}$ locus in New Orleans sites 1 and 4 , in addition to the $B$ allele at Idh locus in New Orleans site 1 mentioned above.

Mean expected heterozygosity estimates for populations during the study period are given in table 2. One-way ANOVA was carried out on average expected heterozygosity ( $H_{\exp }$, transformed to $\arcsin \sqrt{H_{\text {exp }}}$, Zar (1984)) for each population over all the sampling dates. There were no significant differences in mean heterozygosity in all comparisons of all populations. Although many of the correlations between sampling date and mean heterozygosity, mean number of alleles and per cent of loci polymorphic were negative, none were statistically significant at the 5 per cent level. Mean expected heterozygosity compared by ANOVA among all populations gave no differences significant at the 5 per cent level. Mean genetic distance (Nei's unbiased (Nei 1978) averaged over all the populations for each of the 5 sampling dates, table 3) did not indicate a systematic increase or decrease in divergence levels during the period of study.

The variance in allele frequencies was partitioned into variance among cities and among locations within cities for samples collected in the summer of 1986 and in the fall of 1988 (table 4). As previously reported by Black et al. $(1988 a, b)$, most of the variation at both sampling dates was attributable to variation within locations and only a small proportion of the total to variation among locations. In the summer of $1986,86 \cdot 3$ per cent of the total variation was attributable to variance among locations within cities, and the remaining 13.7 per cent to variance among cities. In the fall of 1988 , the corresponding figures were 85.6 and 14.4 per cent, respectively.

\section{DISCUSSION}

In this paper, we presented the results of a threeyear study on temporal and spatial variation in population genetic structure of Ae. albopictus, a recent arrival to the continental U.S. Our primary objective was to determine if we could detect in Ae. albopictus all or some of the consequences of drift often claimed to be associated with colonisation by a small number of individuals (e.g., Mayr, 1963). Although decreased genetic variation has been demonstrated in some colonising species (e.g., Bryant et al., 1981; Easteal, 1988, Johnson, 1988, Schwaegerle and Schaal, 1979), it is not known how early after the colonisation event the effects of drift might be detectable and if such effects are a necessary consequence of colonisation.

Allele frequencies in the U.S. populations of Ae. albopictus changed significantly, albeit seemingly randomly, during the study period. Drift at the local level (Black et al., 1988a), is probably 
Table 2 Estimates of mean expected heterozygosity for Aedes albopictus at each of the sampling dates. The mean sample size per locus is given immediately above the estimate

\begin{tabular}{|c|c|c|c|c|c|}
\hline \multirow[b]{2}{*}{ Location } & \multicolumn{5}{|c|}{ Mean expected heterozygosity ( $x \pm$ S.E.M.) } \\
\hline & S 86 & S 87 & F 87 & S 88 & F 88 \\
\hline & & 38 & 14 & 38 & 38 \\
\hline \multirow[t]{2}{*}{ Brazoria } & - & $0.271 \pm 0.063$ & $0 \cdot 283 \pm 0 \cdot 101$ & $0 \cdot 314 \pm 0 \cdot 101$ & $0.340 \pm 0.073$ \\
\hline & 38 & & 40 & 38 & 37 \\
\hline \multirow[t]{2}{*}{ Chambers } & $0.321 \pm 0.056$ & - & $0 \cdot 286 \pm 0 \cdot 084$ & $0 \cdot 271 \pm 0.083$ & $0.327 \pm 0.086$ \\
\hline & 30 & 37 & 37 & 40 & 40 \\
\hline \multirow[t]{2}{*}{ Galveston } & $0.328 \pm 0.081$ & $0.347 \pm 0.097$ & $0.271 \pm 0.082$ & $0.234 \pm 0.077$ & $0.286 \pm 0.086$ \\
\hline & & 50 & 15 & 39 & \\
\hline \multirow{2}{*}{ Fort Bend } & - & $0 \cdot 388 \pm 0.089$ & $0 \cdot 299 \pm 0 \cdot 105$ & $0 \cdot 316 \pm 0 \cdot 103$ & $0.324 \pm 0.076$ \\
\hline & 11 & 40 & 39 & 39 & 39 \\
\hline Liberty & $0.292 \pm 0.030$ & $0.353 \pm 0.090$ & $\begin{array}{l}0 \cdot 266 \pm 0 \cdot 097 \\
26\end{array}$ & $\begin{array}{l}0 \cdot 333 \pm 0.089 \\
39\end{array}$ & $\begin{array}{l}0 \cdot 282 \pm 0 \cdot 070 \\
39\end{array}$ \\
\hline \multirow[t]{2}{*}{ Montgomery } & - & - & $0.309 \pm 0.103$ & $0.287 \pm 0.094$ & $0 \cdot 352 \pm 0 \cdot 090$ \\
\hline & 42 & 32 & & 39 & 40 \\
\hline Area 32 & $\begin{array}{l}0 \cdot 274 \pm 0 \cdot 090 \\
42\end{array}$ & $\begin{array}{l}0 \cdot 314 \pm 0 \cdot 104 \\
32\end{array}$ & - & $\begin{array}{l}0 \cdot 270 \pm 0 \cdot 091 \\
39\end{array}$ & $\begin{array}{l}0.265 \pm 0.085 \\
38\end{array}$ \\
\hline Area 34 & $\begin{array}{l}0 \cdot 274 \pm 0.090 \\
38\end{array}$ & $\begin{array}{l}0 \cdot 310 \pm 0 \cdot 106 \\
44\end{array}$ & $\overline{39}$ & $\begin{array}{l}0.332 \pm 0.092 \\
39\end{array}$ & $0.303 \pm 0.076$ \\
\hline \multirow[t]{2}{*}{ Area 61} & $0 \cdot 380 \pm 0 \cdot 101$ & $0 \cdot 273 \pm 0.095$ & $0.273 \pm 0.082$ & $0 \cdot 314 \pm 0.095$ & $\overline{-1}$ \\
\hline & 37 & 39 & 18 & 38 & 40 \\
\hline Area 203 & $\begin{array}{l}0 \cdot 362 \pm 0 \cdot 105 \\
25\end{array}$ & $\begin{array}{l}0 \cdot 346 \pm 0 \cdot 102 \\
38\end{array}$ & $\begin{array}{l}0 \cdot 276 \pm 0 \cdot 102 \\
21\end{array}$ & $\begin{array}{l}0 \cdot 260 \pm 0.092 \\
38\end{array}$ & $\begin{array}{l}0 \cdot 222 \pm 0.079 \\
40\end{array}$ \\
\hline Area 218 & $\begin{array}{l}0.349 \pm 0.099 \\
10\end{array}$ & $\begin{array}{l}0 \cdot 274 \pm 0.080 \\
37\end{array}$ & $\begin{array}{l}0.310 \pm 0.094 \\
20\end{array}$ & $\begin{array}{l}0.245 \pm 0.094 \\
35\end{array}$ & $\begin{array}{l}0.256 \pm 0.072 \\
40\end{array}$ \\
\hline Area 509 & $\begin{array}{l}10 \\
0 \cdot 296 \pm 0.078\end{array}$ & $0.282 \pm 0.091$ & $0.276 \pm 0.092$ & $\begin{array}{l}0 \cdot 277 \pm 0.099 \\
38\end{array}$ & $0.248 \pm 0.099$ \\
\hline New Orl. 1 & $\begin{array}{l}0.354 \pm 0.089 \\
19\end{array}$ & - & - & $\begin{array}{l}0 \cdot 162 \pm 0 \cdot 070 \\
38\end{array}$ & - \\
\hline New Orl. 2 & $\begin{array}{l}0 \cdot 224 \pm 0.083 \\
22\end{array}$ & - & - & $\begin{array}{l}0 \cdot 207 \pm 0 \cdot 060 \\
39\end{array}$ & - \\
\hline New Orl. 4 & $\begin{array}{l}0 \cdot 274 \pm 0 \cdot 069 \\
16\end{array}$ & - & - & $\begin{array}{l}0 \cdot 269 \pm 0 \cdot 084 \\
38\end{array}$ & - \\
\hline Jacksonville & $\begin{array}{l}0 \cdot 211 \pm 0 \cdot 089 \\
45\end{array}$ & - & - & $\begin{array}{l}0.352 \pm 0.093 \\
40\end{array}$ & - \\
\hline Memphis & $0.122 \pm 0.069$ & - & - & $0.280 \pm 0.080$ & - \\
\hline
\end{tabular}

Abbreviations: S 86: Summer 86; S 87: Summer 87; F 87: Fall 87; S 88: Summer 88; F 88: Fall 88.

Table 3 Temporal change in mean genetic distance (Nei's unbiased) in US and Texas populations of Aedes albopictus. The genetic distances among all populations at a given sampling date were averaged to obtain the values shown. $n$ represents the number of values in the genetic distance matrix

\begin{tabular}{lll}
\hline Sampling date & $n$ & $\begin{array}{l}\text { Mean genetic distance } \\
( \pm \text { S.E.M. })\end{array}$ \\
\cline { 3 - 3 } Texas & & \\
$\quad$ Summer 1986 & 28 & $0.030 \pm 0.004$ \\
Summer 1987 & 45 & $0.042 \pm 0.004$ \\
Fall 1987 & 45 & $0.036 \pm 0.004$ \\
Summer 1988 & 66 & $0.056 \pm 0.004$ \\
Fall 1988 & 55 & $0.029 \pm 0.004$ \\
United States & & \\
$\quad$ Summer 1986 & 10 & $0.109 \pm 0.020$ \\
$\quad$ Summer 1988 & 10 & $0.112 \pm 0.012$ \\
\hline
\end{tabular}

continuing. Some of the alleles detected at low frequencies in 1986 were not detected in subsequent samples, suggesting loss through genetic sampling. For example, in New Orleans site 1, the $I d h$ locus, which was polymorphic in all the populations examined (including New Orleans site 1 in 1986), became monomorphic in a few generations. Control efforts involving insecticides in some parts of the U.S. may also have contributed to the loss of some low frequency alleles. Selection as the causal factor is unlikely because of the short time involved and the lack of a systematic change in allele frequencies at the $I d h$ locus in any of the other populations. Despite the loss of some low frequency alleles, there was no significant overall change in mean heterozygosity over the three-year period; none of the correlations between time and 
Table 4 The variance of allele frequencies of Aedes albopictus partitioned into variance among locations within cities and among cities. Variance components were combined among all loci. See text for further details

\begin{tabular}{llll}
\hline Sampling date & Source & $\begin{array}{l}\text { Variance } \\
\text { component }\end{array}$ & $\begin{array}{l}\text { Per cent } \\
\text { of total }\end{array}$ \\
\hline Summer 1986 & Within locations & 0.241 & 86.7 \\
& Among cities & 0.037 & 13.3 \\
& Total & 0.278 & \\
Summer 1988* & Within locations & 0.308 & 85.6 \\
& Among cities & 0.053 & 14.4 \\
& Total & 0.361 & \\
\hline
\end{tabular}

* Includes Texas samples from the fall of 1988 and the U.S. samples from the summer of 1988

the various measures of genetic variation were statistically significant, indicating that genetic variation is being maintained within populations.

In addition, there was no significant change in variance of allele frequencies among locations within cities or among cities over the three-year period. In 1986, the variance component for among locations within cities was 86.7 per cent and in 1988, 85.6 per cent. Black et al., $(1988 b)$ found that variance among locations within regions in Malaysia and Borneo was $79 \cdot 3$ per cent. The variance of allele frequencies among locations within cities in each case is about 4-5 times greater than that among cities. Although we did not partition the variance at each of the five sampling dates for the Texas populations, the lack of a systematic change in the divergence levels among these populations (table 3 ) suggests that there was no change in the variance of allele frequencies over time (Falconer, 1981). Therefore, with regard to variance components, the U.S. populations were similar to those from a native habitat soon after establishment and remained so after several generations in the new environment. Strong local differentiation also exists in the ribosomal DNA nontranscribed spacer region of Ae. albopictus (Black et al., 1989).

Black et al. $(1988 a, b)$ suggested that local genetic drift could arise from a patchy distribution of breeding sites and dispersal habits of $A e$. albopictus, which in the U.S. breeds primarily in tyre dumps in urban areas. Each dump may contain thousands of tyres and is usually separated from others by a considerable distance and urban structures creating barriers to dispersal. In very large tyre dumps, the population may be further subdivided because Ae. albopictus disperses only about 150-200 $\mathrm{m}$ from its breeding sites (Hawley, 1988).
Our results confirm those of Black et al. $(1988 a, b)$ that genetic drift is a characteristic of the local breeding structure of Ae. albopictus. We have also shown that breeding structure has not changed as a result of the colonisation. The lack of any "founder effects" (Mayr, 1963), other than the loss of some rare alleles, suggests several possibilities. For example, it could be too early to detect significant loss of within population genetic variation.

Direct and circumstantial evidence, however, suggests that the dynamics of colonisation of the U.S. by Ae. albopictus is a more likely explanation for the observed patterns of allele frequency variation. First, it is probable that there was one very large introduction and/or repeated introductions of Ae. albopictus into the U.S. The high levels genetic variation and the local breeding structure of the U.S. populations, both comparable to those in a native habitat (Black et al., 1988b), support this view. Second, there was considerable movement of population within the U.S. subsequent to establishment in Houston with a rapid spread of Ae. albopictus to at least 20 states in about 4-5 years. Such movement must have resulted in considerable gene flow. For example, the $\mathrm{H}_{\text {exp }}$ for Memphis increased from 0.122 in 1986 to 0.280 in 1988 and for Jacksonville from $0 \cdot 211$ to $0 \cdot 352$. Third, a rough estimate of effective population sizes based on $F_{\text {st }}$ values (Easteal, 1985) indicated an increase in the U.S. from the summer of 1986 through the fall of 1988. (The estimates for Ae. albopictus in Texas are: 102, 134, 155, 134 and 260 for each of the five sampling dates, respectively. We assumed that: Ae. albopictus goes through ten generations per year, twenty generations have elapsed in the U.S. before the first sampling and five generations elapsed between sampling in the summer and the sampling in the fall of each year). This suggests that Ae. albopictus population is expanding, perhaps aided by an influx of new genetic material from locations within the U.S. A large founder population, gene flow and a rapid increase in population size may impede the loss of genetic variation during founder events (Falconer, 1981; Janson, 1987; Nei et al., 1975).

Our results indicate that Ae. albopictus was introduced into the U.S. with most of the genetic variation intact. This may have substantially enhanced its chances for establishment. The large founder population and rapid increase in population size also suggest that a future loss of genetic variation, as a direct consequence of the colonisation event, is unlikely. 
Acknowledgments We thank Dr E. D. Freytag, Dr J. D. Miller and $\mathrm{MrC}$. B. Pumpuni for providing some of the mosquito samples used in this study, $\mathrm{Dr}$ W. A. Hawley for valuable discussion and $\mathrm{Mr} \mathrm{B}$. J. Turco for raising mosquitoes. This study was supported by NIH grant 5R01 AI-21443 to K.S.R.

\section{REFERENCES}

BLACK, W. C. IV, FERRARI, J. A., RAI, K. S. AND SPRENGER, D. 1988 . Breeding structure of a colonizing species: Aedes albopictus (Skuse) in the United States. Heredity, 60, 173181.

BLACK, W. C. IV, HAWLEY, W. A., RAI, K. S. AND CRAIG, G. B. $1988 \mathrm{~b}$. Breeding structure of a colonizing species: Aedes albopictus (Skuse) in peninsular Malaysia and Borneo. Heredity, 61, 439-446.

BLACK, W. C. IV, McLAIN, D. K. AND RAI, K. S. 1988. Patterns of variation in rDNA cistron within and among world populations of a mosquito Aedes albopictus (Skuse). Genetics, 121, 539-550.

BRYANT, E. C., DYK, H. V. AND DELDEN, w. v. 1981. Genetic variability of the face fly, Musca autumnalis De Geer, in relation to a population bottleneck. Evolution, 35, 872-881.

CENTERS FOR DISEASE CONTROL. 1987. Update: Aedes albopictus infestation United States, Brazil. Morb. Mort. Weekly Report., 36, 769-773.

CRAVEN, R. B., EliASON, D. A., FRANCY, D. B., REITER, P., CAMPOS, E. G., JAKOB, W. L., SMITH, G. C., BOZZI, C. J., MOORE, C. G., MAUPIN, G. O., AND MONATH, T. P. 1988. Importation of Aedes albopictus and other exotic mosquito species into the United States in used tires from Asia. $J$. Mosq. Cont. Assoc., 4, 138-142.

EADS, R. B. 1972. Recovery of Aedes albopictus from tires shipped to the United States ports. Mosq. News, 32, 113114.

EASTEAL, S. 1985. The ecological genetics of introduced populations of the giant toad Bufo marinus II: Effective population size. Genetics, 110, 107-122.

EASTEAL, S. 1988. Range expansion and its genetic consequences in populations of the giant toad Bufo marinus. In Hecht M. K. and Wallace, B. (eds) Evolutionary Biology, 23, 49-84.
FALCONER, D. S. 1981. Introduction to Quantitative Genetics, 2nd edn. Longman Inc. New York.

HAWLEY, W. A. 1988. The biology of Aedes albopictus. J. Amer. Mosq. Cont. Assoc. (suppl. 1), 1-40.

HAWLey, W. A., REITER, P., COPELAND, R. S., PUMPUNI, C. B., AND CRAIG, G. B. 1987. Aedes albopictus in North America: Probable Introduction in tires from northern Asia. Science, 236, 1114-1116.

JANSON, K. 1987. Genetic drift in small and recently founded populations of the marine snail Littorina saxatilis. Heredity, $58,31-37$.

JOHNSON, M.S. 1988. Founder effects and geographic variation in the land snail Theba pisana. Heredity, 61, 133-142.

MAYR, E. 1963. Animal Species and Evolution. Harvard Univ. Press, Cambridge Mass.

NEI, M. 1978. Estimation of average heterozygosity and genetic distance from a small number of individuals. Genetics, 89 , 583-590.

NEI, M., MARUYAMA, T. AND CHAKRABORTY, R. 1975. The bottleneck effect and genetic variability in populations. Evolution, 29, 1-10.

REITER, P. AND DARSIE, JR., R. F. 1984. Aedes albopictus in Memphis, Tennessee (USA): An achievement of modern transportation? Mosq. News, 4, 396-399.

SCHWAEGERLE, K. E. AND SCHAAL, B. A. 1979. Genetic variability and founder effect in the pitcher plant Sarracenia purpurea L. Evolution, 33, 1210-1218.

SPRENGER, D., AND WUITHIRANYAGOOL, T. 1986. The discovery and distribution of Aedes albopictus in Harris County, Texas. J. Am. Mosq. Cont. Assoc., 2, 217-219.

SWOFFORD, D. L. AND SELANDER, R. B. 1981. BIOSYS-1: a FORTRAN program for the comprehensive analysis of electrophoretic data in population genetics and systematics. J. Hered., 72, 281-283.

TAYLOR, C. E. AND GORMAN, G. C. 1975. Population genetics of a "colonizing" lizard: Natural selection for allozyme morphs in Anolis grahami. Heredity, 35, 241-247.

WRIGHT, S. 1978. Evolution and the Genetics of Populations. Vol. IV. Variability Within and Among Natural Populations. University of Chicago Press, Chicago.

ZAR, J. H. 1984. Biostatistical Analysis, 2nd edn. Prentice-Hall, Englewood Cliffs, New Jersey. 